\title{
Comparison of junction temperature evaluations in a power IGBT module using an IR camera and three thermo-sensitive electrical parameters
}

\author{
Laurent DUPONT \\ French Institute of Science \& Technology for Transport \\ Development and Networks (IFSTTAR) \\ New Technologies Laboratory (LTN) \\ Versailles, France \\ Laurent.Dupont@ifsttar.fr
}

\author{
Yvan AVENAS, Pierre-Olivier JEANNIN \\ Grenoble Electrical Engineering Laboratory (G2Elab) \\ UMR CNRS 5269 - Grenoble-INP -UJF \\ Grenoble, France \\ Yvan.Avenas@g2elab.grenoble-inp.fr
}

\begin{abstract}
The measurement of the junction temperature with thermo-sensitive electrical parameters (TSEPs) is largely used by electrical engineers or researchers but the obtained temperature value is generally not verified by any referential information of the actual chip temperature distribution. In this paper, we propose to use infrared (IR) measurements in order to evaluate the relevance of three commonly used TSEP with IGBT chips: the saturation voltage under a low current, the gateemitter voltage and the saturation current. The IR measurements are presented in details with an estimation of the emissivity of the black paint deposited on the power module. The temperatures obtained with IR measurement and with the different TSEPs are then compared in two cases: the use of only one chip and the use of two paralleled chips.
\end{abstract}

\section{INTRODUCTION}

The junction temperature measurement of a power semiconductor device can be used to characterize thermal performances of its package and as a damage indicator of the power module principally for the detection of a delaminating process in the assembly [1]. Three main methods are used today to evaluate the junction temperature of power semiconductor devices [2]: optical methods, physically contacting methods and electrical methods. The main optical methods are local infrared sensors [3], optical fibers [4], infrared microscope [5] and infrared camera [6]. The main advantage of the IR camera is the possibility to directly obtain a temperature map of the power device. The junction temperature measurement can also be done directly contacting the chip with a thermo-sensitive material. The main solution is the use of thermal probes (thermistors or thermocouples) [7]. Although optical and physically contacting methods can be really accurate, the measurement time can hardly be lower than $1 \mathrm{~ms}$ due to the electronic treatment or to the thermal capacitance of thermo-sensible materials. This is the reason why the common way to measure a junction temperature is the use of a thermo-sensitive electrical parameter (TSEP): the chip is itself the temperature sensor. However the accuracy obtained by this technique can be discussed because the chip temperature is very inhomogeneous. Therefore large junction temperature differences can be obtained using different techniques. In case of power MOSFET in TO220 packages, Jakopovic and al. [8] show that the measured thermal resistance can vary from $0.9 \mathrm{~K} / \mathrm{W}$ using the channel resistance as a TSEP, to $1.25 \mathrm{~K} / \mathrm{W}$ using the threshold voltage, i.e. a $25 \%$ difference between each measurement. In order to better know the junction temperature value of an IGBT chip given by the saturation voltage $\mathrm{V}_{\text {ce,sat }}$ under a low current method, Schmidt and Scheuermann [6] compare it with the temperature map given by an IR camera. They show that the junction temperature given by this TSEP is really close to the average surface temperature.

The goal of this paper is to provide complementary results to these studies. The surface temperature map of IGBT dies is measured with an infrared (IR) camera and compared with the junction temperature given by three usual TSEPs: the saturation voltage under a low current $\mathrm{V}_{\text {ce,sat }}$ [6], the gateemitter voltage $V_{\text {ge,I }}[9]$ and the saturation current $I_{\text {css }}[10]$. In the first part, the studied power module and the experimental setup are described. Then the principle of the temperature estimation including a calibration of the emissivity of the black paint is presented. Finally, calibration curves of the different TSEPs and temperature measurements are presented and discussed.

\section{EXPERIMENTAL SETUP}

\section{A. Presentation of the device under test}

All test campaigns are performed with a simplified power assembly composed of two transistor chips soldered on a copper substrate. The power module is developed without gel in order to carry out infrared temperature measurements of the 
power components. The transistors are $600 \mathrm{~V}-200 \mathrm{~A}$ INFINEON IGBTs (SIGC100T60R3) with an aluminum metallization on the top surface. The power module and the electrical topology with two IGBTs are presented in Fig. 1.

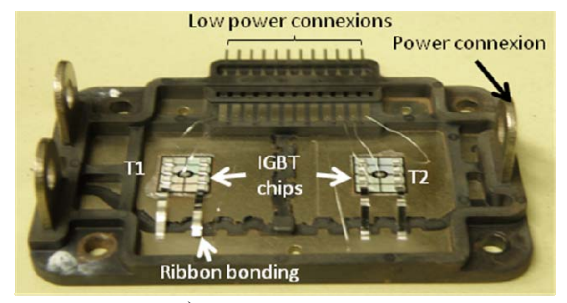

a)

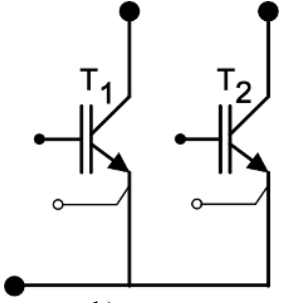

b)
Figure 1. Power module dedicated to tests (a) and electrical topology (b).

The schematic cross section of the power module fixed on the water cooling system is presented in Fig. 2. The IGBTs power electrical connections are made with aluminum ribbons. They have been chosen because the area viewed by the IR camera is larger than this obtained with wire bonding [6].

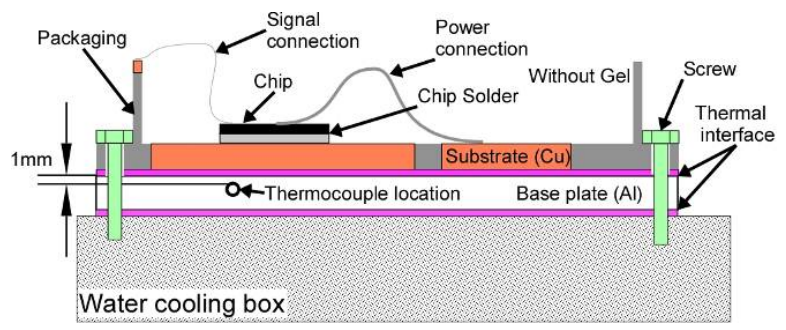

Figure 2. Power module assembly fixed on a water cooling box.

Fig. 3 presents an example of the temperature distribution on a $100 \mathrm{~W}$ black painted dissipating IGBT.

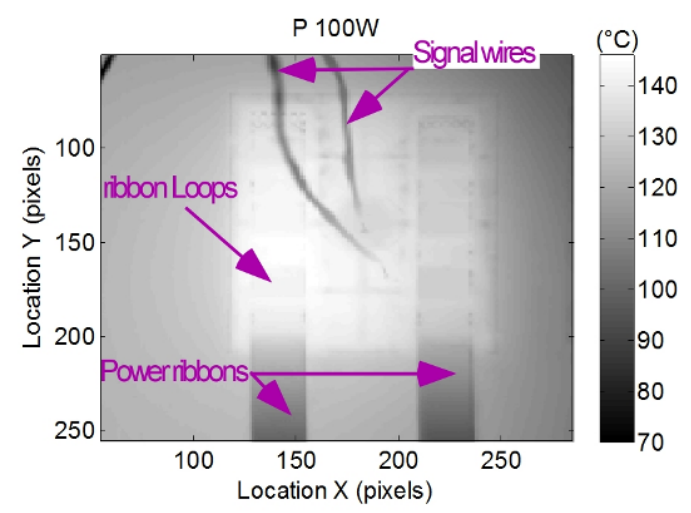

Figure 3. Temperature distribution on a dissipating IGBT.

\section{B. Presentation of the test bench}

The test bench is developed around an infrared camera mounted on a manual positioning solution (Fig. 4). The infrared camera is a TITANIUM 550M CEDIP system (SC7500 FLIR). The measurements are done in the middle wave range $(3.7 \mu \mathrm{m}$ to $4.8 \mu \mathrm{m})$ with $\mathrm{InSb}$ matrix sensors of $320 \times 256$ active cells. The spatial resolution of the infrared image is defined with an adapted lens which permits a pixel size smaller than $100 \mu \mathrm{m}$ per $100 \mu \mathrm{m}$.
The temperature of the black painted power module is controlled from $40^{\circ} \mathrm{C}$ to $180^{\circ} \mathrm{C}$ by the cold plate connected to a temperature control instrument (JULABO Presto). All electrical measurements are made with a DEWETRON data acquisition system (DEWE5000). The voltage accuracy of this system is $0.04 \%$. All measurements are isolated each other and the bandwidth is $300 \mathrm{kHz}$. All TSEPs are measured with a specific electronic circuit. This circuit is driven by a LabView program and a NI USB-6259 board connected to a computer.

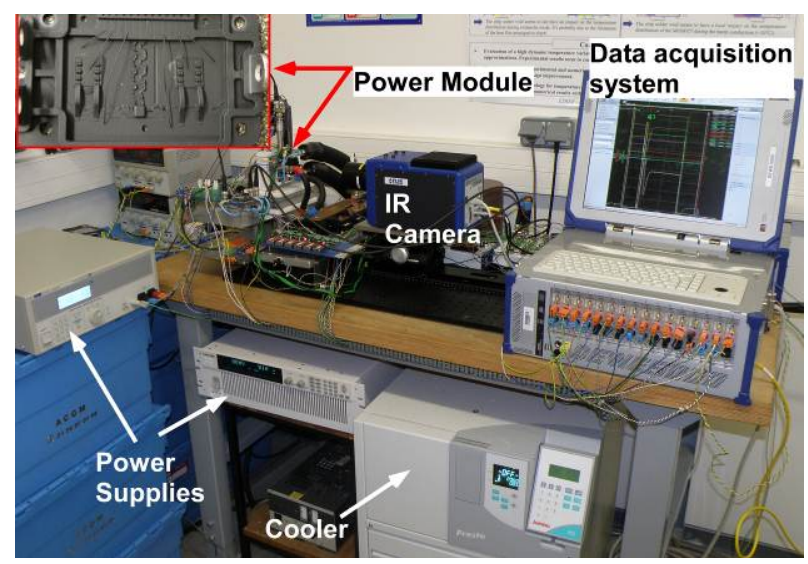

Figure 4. Test bench for IR and TSEP measurements.

\section{INFRARED (IR) MEASUREMENTS}

\section{A. Control and calibration of the surface emissivity}

Large temperature measurement errors may be done using infrared measurements due to the surface degradation of materials and the intrinsic low emissivity of aluminum with a complex geometry of the active parts $(<0.1)$ [11]. Thus, the infrared temperature measurements of power components conduct to control the surface emissivity with a paint solution. Experimental campaigns are conducted in order to evaluate the emissivity of two selected paints adapted for operating temperatures from $40^{\circ} \mathrm{C}$ to $180^{\circ} \mathrm{C}$ (MOTIP and ACRYL RAL). The paint coats are deposited on a copper base plate (5mm thick) which is thermally controlled with a cooling box from $40^{\circ} \mathrm{C}$ to $200^{\circ} \mathrm{C}$. These elements are thermally isolated with PTFE part which limits the convective and radiative heat transfers and thus the temperature gradients inside the base plate. Windows are realized in the PTFE part in order to make temperature infrared measurements of the painted surface. Fig. 5 presents the test bench used to qualify the emissivity of different paint solutions versus the temperature.

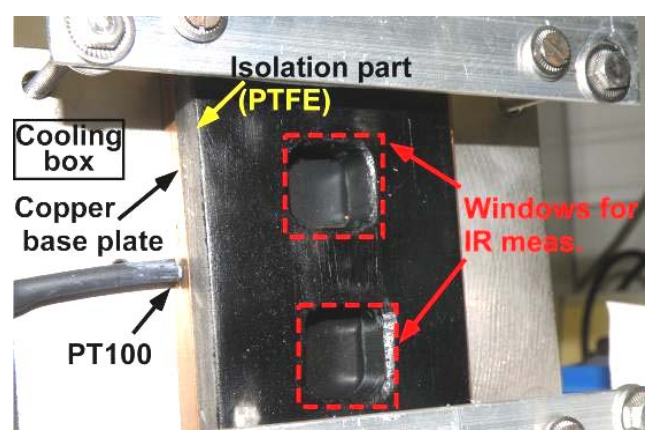

Figure 5. Test bench for the emissivity evaluation. 
The referential temperature $\left(\mathrm{T}_{\text {ref }}\right)$ is evaluated with a RTD temperature sensor (PT100 class $1 / 10 \pm 0.06^{\circ} \mathrm{K}$ ) connected to a 6.5 digit precision multimeter FLUKE 8846A. The propagated error of the measurement chain is calculated close to $\pm 0.12^{\circ} \mathrm{K}$. This temperature measurement is located in the center of the copper base plate close to the surface measurement areas. Table I presents the synthesis of the paints and the conditions of use.

TABLE I. DETAILS OF EVALUATED PAINTS

\begin{tabular}{|l|c|c|c|}
\hline \multicolumn{1}{|c|}{ Paints } & $\begin{array}{c}\text { Number } \\
\text { of coats }\end{array}$ & $\begin{array}{c}\text { Times between } \\
\text { 2 coats (s) }\end{array}$ & $\begin{array}{c}\text { Finish } \\
\text { conditions }\end{array}$ \\
\hline ACRYL RAL 9005 & $8 / 12 / 16 / 18 / 20 / 24$ & 180 & $60 \mathrm{~min} / 25^{\circ} \mathrm{C}$ \\
\hline MOTIP - 04031 & $8 / 12 / 16 / 24$ & 60 & $60 \mathrm{~min} / 160^{\circ} \mathrm{C}$ \\
\hline
\end{tabular}

The infrared temperature measurements are performed with FLIR software emissivity parameter equal to one $\left(\mathrm{T}_{\mathrm{IR} @ \varepsilon=1}\right)$. In first, an evaluation of the coats number impact is conducted for a referential temperature close to $100^{\circ} \mathrm{C}$. A mean value is calculated from one hundred infrared measurement images in order to limit the mechanical vibration impact. As we can see in the Fig. 6, the number of paint coats impacts on the standard deviation of the temperature measurements (Std MOTIP and STD ACRYL RAL) and on the difference between $\mathrm{T}_{\text {ref }}$ and $\mathrm{T}_{\mathrm{IR} @ \varepsilon=1}$ which is representative of the paint emissivity value (DT MOTIP and DT ACRIL RAL). The ACRYL RAL solution presents a higher dispersion due to difficult conditions to adjust the paint coat deposition.

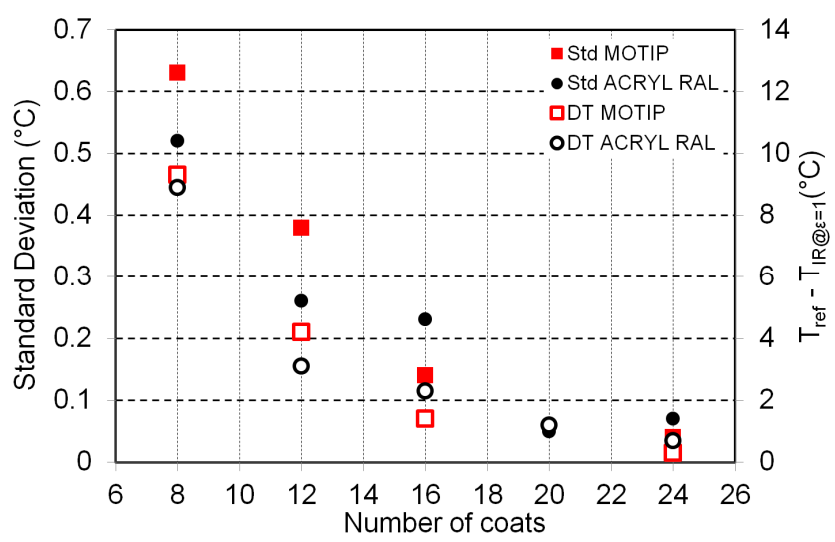

Figure 6. Influence of the coats number.

The emissivity evaluation versus temperature has been conducted for both paints from $40^{\circ} \mathrm{C}$ to $180^{\circ} \mathrm{C}$. The emissivity evaluation is realized with the same test bench. After the thermal equilibrium of the bench in the range from $40^{\circ} \mathrm{C}$ and $200^{\circ} \mathrm{C}$, the infrared temperature measurement is made with an emissivity equal to one. This measurement on a dedicated area is compared with the referential temperature measurement obtained with the PT100 sensor. A first Matlab program is developed with dedicated FLIR functions. The corrected emissivity of the paint is estimated using the program in order to obtain a mean temperature as close as possible to the referential temperature one. Fig. 7 presents the results of the corrected emissivity evaluation as a function of the temperature for both the MOTIP and ACRYL paints.

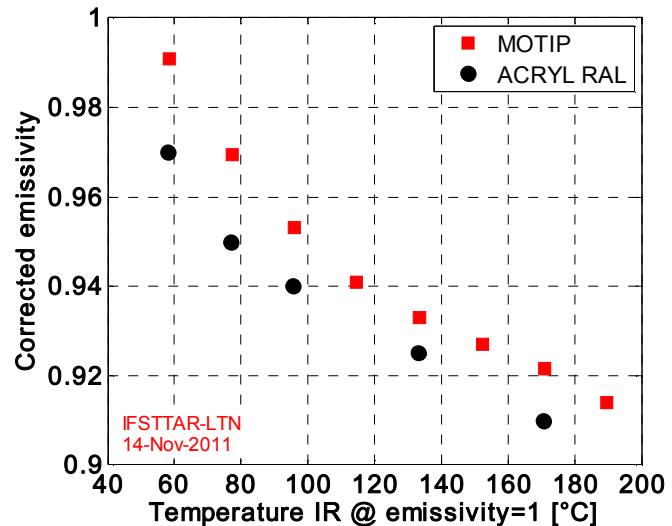

Figure 7. Evaluation of the emissivity versus the infrared temperature measurement.

An extrapolation of the corrected emissivity variation versus the temperature is calculated. A quadratic interpolation is used to fit the experimental results. Equation (1) presents the expression of the corrected emissivity interpolation for the MOTIP paint.

$$
\begin{aligned}
\mathcal{E}_{\text {corr MOTIP }}= & 3.6810^{-6} \times\left(T_{I R @ \varepsilon=1}\right)^{2} \\
& -1.462110^{-3} \times T_{I R @ \varepsilon=1}+1.0618
\end{aligned}
$$

where $\varepsilon_{\text {corrMOTIP }}$ is the corrected emissivity which is calculated from $T_{I R @_{\varepsilon}=1}$ as the infrared temperature measurement with a fixed emissivity equal to one.

In this paper, all infrared temperature measurements of IGBT dies are made with the MOTIP black paint. In one hand, the coat number is fixed to twenty four in order to guaranty the good temperature measurement in steady-state conditions. In another hand, the infrared temperature measurements are calculated from the averaging of one hundred infrared acquisitions.

\section{B. Methodology for an evaluation of the chip temperature}

The temperature evaluation of the chip is carried out in the thermal steady-state conditions. A second Matlab program has been developed in order to extract the useful chip temperature. As presented in Fig. 8a, the infrared image is analyzed in order to perform an orthogonal adjustment with the edge detection of the IGBT chip under test. Fig. 8b shows the IGBT view after automated cropping.

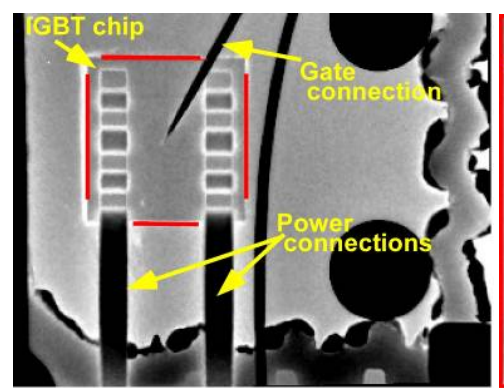

a)

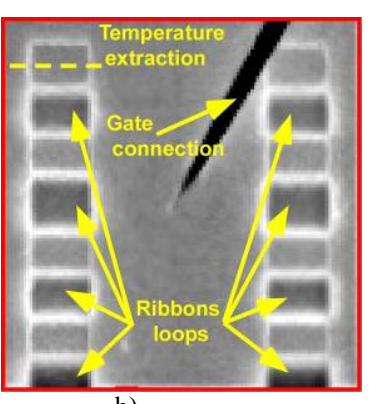

b)
Figure 8. Image extraction of the IGBT chip from the infrared acquisition. 
As shown in Fig. 8b, the image of the chip temperature from the infrared acquisition is not directly usable. Fig. 9 shows a schematic presentation of the top view of the IGBT chip with the active parts specified in black color

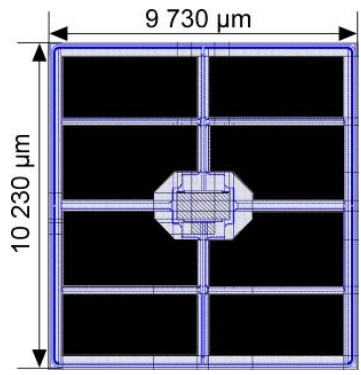

Figure 9. Top view of an IGBT chip (emitter side).

In fact, some elements have to be removed in order to perform the temperature calculation only on the real active areas of the chip:

- The gate connection which crosses the chip image from the right top corner to the center of the chip,

- The power ribbons loops used to connect each active areas of the IGBT chip,

- The inactive areas of the chip which are presented in Fig. 9 (gate pad, passivation...),

- The temperature measurement artifacts due to geometric specifications of ribbons and disturbances due to the paint deposition.

This last point is demonstrated in Fig. 10 with the temperatures extraction along the line presented in Fig. 8b. Nevertheless, the temperature of the ribbons stiches areas is close to this of the active parts of the chip. The temperature error is thus low.

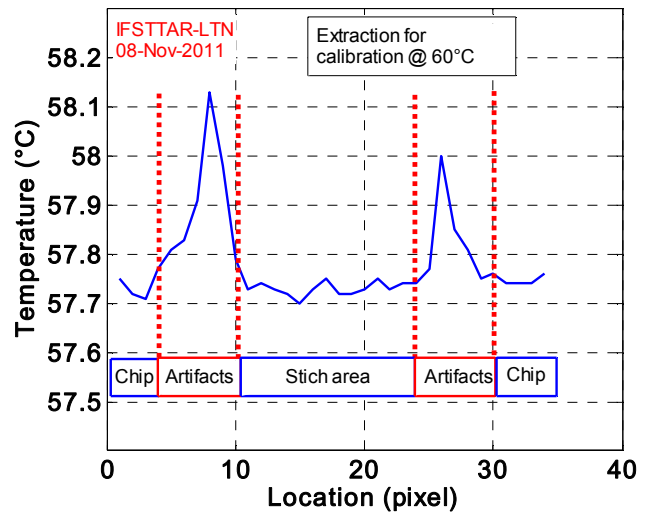

Figure 10. Profile extraction of the IR temperature measurement along a ribbon stich area.

As presented in Fig. 11a, numerical masks are used to exclude the unusable areas of the infrared temperature measurement of the IGBT chip. These black areas define the temperature zones which are excluded for the raw temperature calculation. The temperature initially measured with an emissivity equal to 1 is corrected during the post-treatment with the corrected emissivity expression presented in (1).
Finally, a temperature extrapolation is made with the help of local bilinear fitting adjustments in order to estimate the temperature distribution in the active areas of the IGBT chip (Fig. 11b).

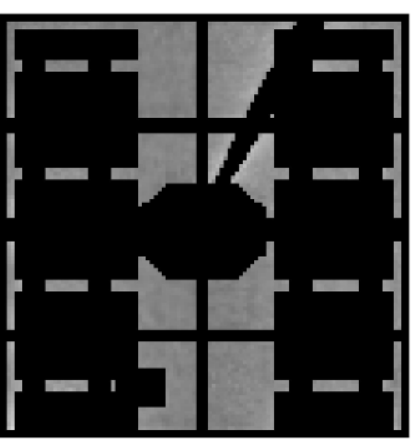

a)

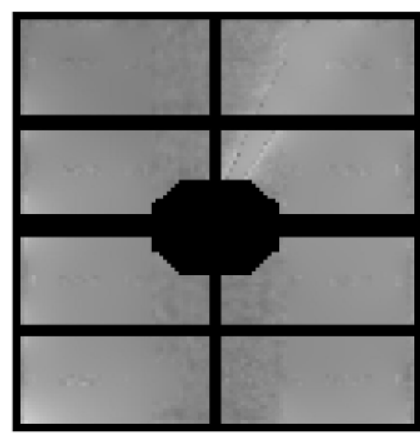

b)
Figure 11. a) Presentation of the masked zones excluded for the raw temperature calculation b) Recomposed IGBT chip temperature distribution.

\section{TSEP CHARACTERIZATION}

In this section the calibration procedure and the measurement conditions are presented for each TSEP. Then we show the dependence of them as a function of the temperature. Due to convection and radiation heat transfers between the module and its environment, the chip temperature is lower than the cold plate temperature. Thus the temperature is measured using the IR camera. The procedure presented in the previous section is used to evaluate the average temperature of the IGBT active part. This average temperature is considered as the chip temperature in the calibration curves. For each TSEP, three characterizations are made, one for IGBT $T_{1}$, one for IGBT $T_{2}$ and another for the two paralleled IGBT.

\section{A. Measurement of the saturation voltage $V_{c e, s a t}$}

This measurement is carried out feeding the IGBT chip with a low current supply $I_{m}$ (Fig. 12). In the tests, $I_{c}$ equals 50 $\mathrm{mA}$ if only one IGBT is tested and equals $100 \mathrm{~mA}$ in the case of two paralleled IGBT. These values are chosen in order to have a linear characterization curve in all the temperature range. The gate-emitter voltage is $15 \mathrm{~V}$. Because the dissipated power is very low in the chip, the current injection can be continuous without any self-heating of the power device.

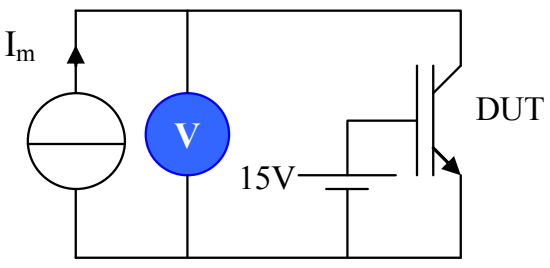

Figure 12. Measurement of $\mathrm{V}_{\mathrm{ce}, \mathrm{sat}}$ as TSEP.

Fig. 13 shows the variation of $\mathrm{V}_{\text {ce,sat }}$ as a function of temperature for $T_{1}, T_{2}$ and $T_{1} / / T_{2}$. The characterization curves are linear with a slope of $-2.3 \mathrm{mV} /{ }^{\circ} \mathrm{C}$. The measurements using $\mathrm{T}_{1}$ and $\mathrm{T}_{2}$ give very close results, the difference between each curve being about $1 \mathrm{mV}$. The temperature error is thus lower than $0.5^{\circ} \mathrm{C}$. Linearity and low variation from one chip to 
another with the same reference make this TSEP very interesting for junction temperature measurements.

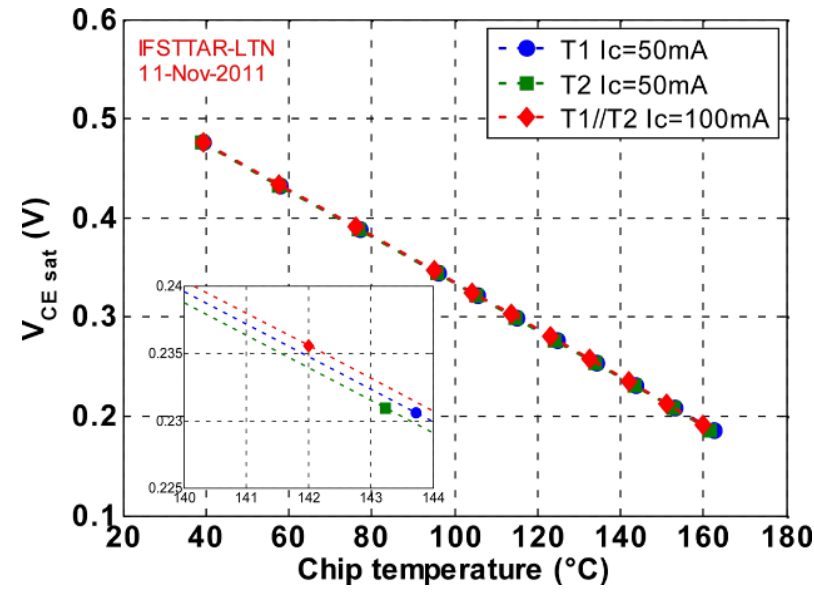

Figure 13. $V_{\text {ce,sat }}$ as a function of the temperature for $T_{1}, T_{2}$ and $T_{1} / / T_{2}$.

\section{B. Measurement of the gate-emitter voltage $V_{g e, I}$}

For this measurement, a voltage source $E=10 \mathrm{~V}$ feed the IGBT chip. The collector current $\mathrm{I}_{\mathrm{c}}=5 \mathrm{~A}$ is regulated acting on the gate voltage. When $T_{1}$ and $T_{2}$ are paralleled, the current $I_{c}$ equals $10 \mathrm{~A}$. In order to limit the self-heating due to the power dissipation during this TSEP evaluation, the calibration procedure is made using a pulsed current. As shown in Fig. $14, I_{c}$ is measured by a $10 \mathrm{~m} \Omega$ shunt resistor $R_{\text {shunt }}$ and regulated by a PI controller.

Despite the use of a pulsed current, a measurement error can be made due to the self-heating of the device during the characterization. Fig. 15 shows the evolution of the gateemitter voltage $\mathrm{V}_{\mathrm{ge}}$ as a function of the time. Therefore an extrapolation method has to be used to decrease this measurement error. Because of the low temperature variation during the measurement time, a linear interpolation as a function of the square root of time can be used $[2,12]$. $\mathrm{V}_{\mathrm{ge}, \mathrm{I}}$ is then estimated calculating the value of the interpolation curve when $\mathrm{t}=\mathrm{t}_{1}$.

Fig. 16 presents $\mathrm{V}_{\mathrm{ge}, \mathrm{I}}$ as a function of the chip temperature for $\mathrm{T}_{1}, \mathrm{~T}_{2}$ and $\mathrm{T}_{1} / / \mathrm{T}_{2}$. The sensitivity is about $-6.5 \mathrm{mV} /{ }^{\circ} \mathrm{C}$ for lower temperatures and $-8 \mathrm{mV} /{ }^{\circ} \mathrm{C}$ for higher temperatures. We can see that a voltage difference of about $100 \mathrm{mV}$ is obtained using $\mathrm{T}_{1}$ instead of $\mathrm{T}_{2}$. The measurement error is thus largely higher than $10^{\circ} \mathrm{C}$. As a conclusion this TSEP varies from one chip to another in the same power module. An accurate temperature measurement needs therefore a calibration of each die. The characterization of $T_{1} / / T_{2}$ gives results being between these obtained with $\mathrm{T}_{1}$ and $\mathrm{T}_{2}$.

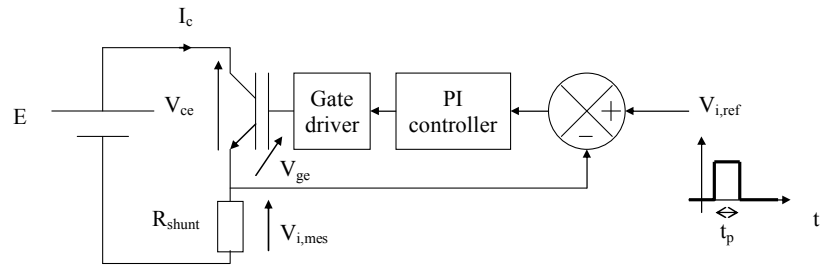

Figure 14. Regulation of the collector current $I_{c}$.

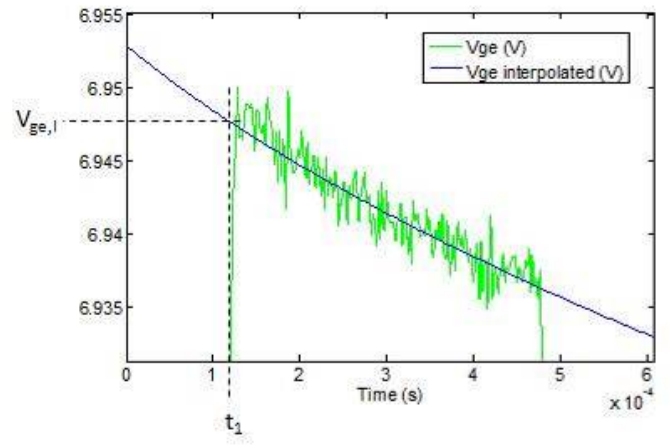

Figure 15. Principle of the $\mathrm{V}_{\mathrm{ge}, \mathrm{I}}$ measurement.

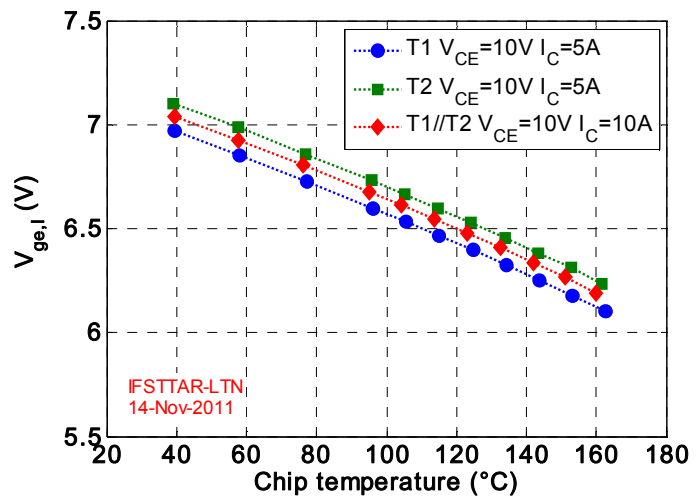

Figure 16. $\mathrm{V}_{\mathrm{ge}, \mathrm{I}}$ as a function of the temperature for $\mathrm{T}_{1}, \mathrm{~T}_{2}$ and $\mathrm{T}_{1} / / \mathrm{T}_{2}$.

\section{Measurement of the saturation current $I_{c s s}$}

The measurement of the saturation current $\mathrm{I}_{\text {css }}$ as a TSEP is made feeding the IGBT by a voltage supply $E=10 \mathrm{~V}$. During this measurement, the gate-emitter voltage is constant and equals $6.4 \mathrm{~V}$. In order to reduce the self-heating of the device, the IGBT is driven by a pulsed gate-emitter voltage. $\mathrm{V}_{\mathrm{ge}}$ oscillations during the measurements are avoided by the use of a regulation loop (Fig. 17).

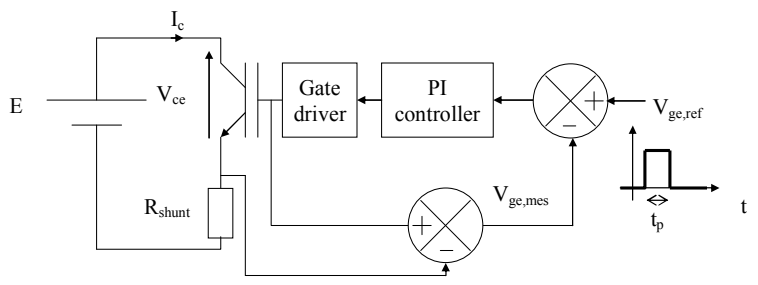

Figure 17. Regulation of the gate-emitter voltage $\mathrm{V}_{\text {ge }}$.

As for the measurement of $\mathrm{V}_{\mathrm{ge}, \mathrm{I}}$, an interpolation process in needed in order to limit the temperature error due to the selfheating of the device. Fig. 18 gives the variation of $\mathrm{I}_{\mathrm{css}}$ as a function of the temperature for $T_{1}, T_{2}$ and $T_{1} / / T_{2}$. This TSEP was not measured in the whole temperature range because the accuracy was poor for low temperatures. As for $\mathrm{V}_{\mathrm{ge}, \mathrm{I}}$, this TSEP is different using $T_{1}$ or $T_{2}$. Logically, the value given in the case of $T_{1} / / T_{2}$ is the sum of both values given using $T_{1}$ and $\mathrm{T}_{2}$. 


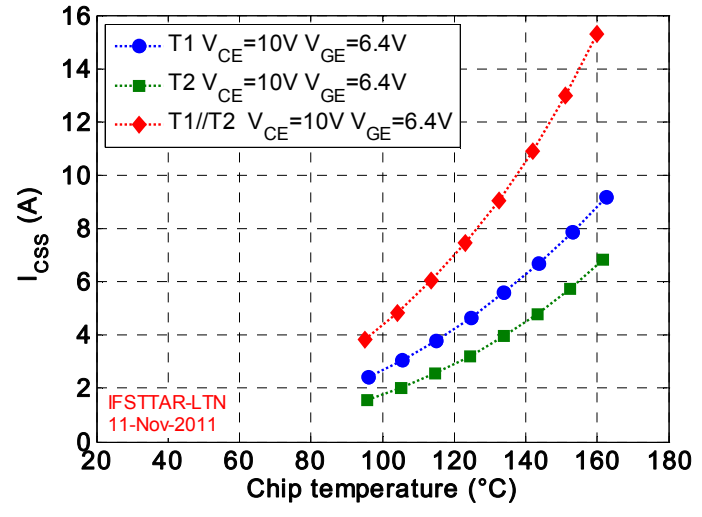

Figure 18. $I_{c s s}$ as a function of the temperature for $T_{1}, T_{2}$ and $T_{1} / / T_{2}$.

\section{TEMPERATURE MEASUREMENTS USING EACH TSEP}

\section{A. Principle of the temperature measurements}

The chip temperature measurements are made in two steps. During the first step, called "dissipation step", the IGBT is fed by a high current source $I_{c}$ inducing a self-heating the device. The gate-emitter voltage equals $15 \mathrm{~V}$ (the IGBT is in saturation conditions). The dissipated power $\mathrm{P}$ is calculated multiplying the collector current value $I_{c}$ and the collector-emitter voltage value $\mathrm{V}_{\text {ce. }}$. The second step, called measurement step, begins when the thermal equilibrium is reached. During this step the device temperature is measured using one of the three presented TSEPs. For this measurement, the electrical circuits depicted in the previous section are used. Fig. 19 summarizes the measurement process. As shown in this figure, a short dead time is introduced between the two steps in order to allow for the switching of all electrical conditions. However the junction temperature decreases during this dead time and during the measurement step. An interpolation procedure is thus needed in order to obtain the temperature value at the end of the dissipation step.

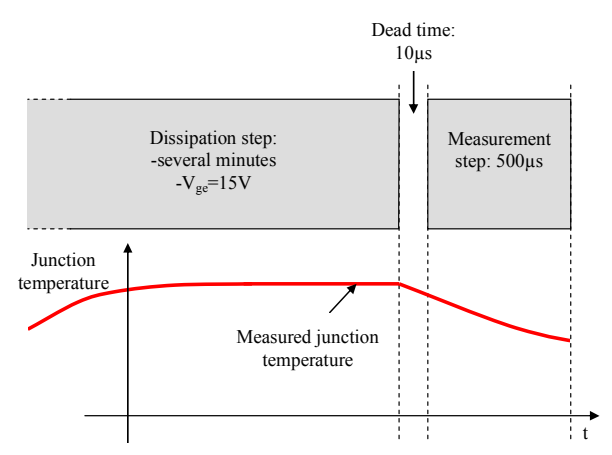

Figure 19. Evolution of the junction temperature during the temperature measurement process.

During the dissipation step, the temperature of the IGBT chip is not homogeneous. For example, Fig. 20 shows in the left an IR image of a dissipating IGBT (in saturation conditions). In the right is traced the temperature along the measure line which shows the large variation of the chip temperature $\left(>30^{\circ} \mathrm{C}\right)$. We can see that in case of dissipation in saturation region, the ribbons are hotter than the IGBT chip due to the high current density value over $100 \mathrm{~A} / \mathrm{mm}^{2}$. A TSEP giving a global temperature value, the comparison with the actual temperature is thus difficult. In the following paragraphs, we have chosen to compare the temperature given by each TSEP with the mean chip surface temperature measured with the technique presented in section III.

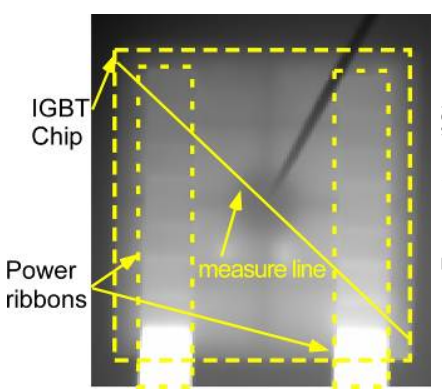

a)

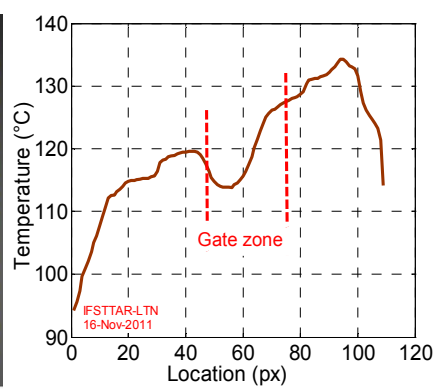

b)
Figure 20. Temperature distribution on a dissipating IGBT (a) and temperature along the measure line (b).

\section{B. Temperature measurements using IGBT $T_{1}$}

Table II presents a comparison between the temperatures obtained with each TSEP $\left(\mathrm{T}_{\mathrm{TSEP}}\right)$ and the mean temperature obtained by IR measurements ( $\left.\mathrm{T}_{\text {meanIR }}\right)$. The studied chip is $\mathrm{T}_{1}$. Three different power levels are used: one close to $45 \mathrm{~W}$, a second close to $70 \mathrm{~W}$ and another close to $95 \mathrm{~W}$. The last column represents the difference between $T_{\text {TSEP }}$ and $T_{\text {meanIR }}$. The $\mathrm{T}_{\mathrm{TSEP}}$ value obtained with $\mathrm{I}_{\mathrm{css}}$ and $\mathrm{P}$ close to $45 \mathrm{~W}$ has not to be taken into account because the measured temperature is not in the range of the calibration curve (Fig. 18).

All TSEP give temperature values in good agreement with the mean temperature obtained with IR measurements. Surprisingly, $\mathrm{V}_{\text {ce,sat, }}$, which is the most used TSEP, gives the results that have the largest differences. On the other hand, $\mathrm{V}_{\text {ge,I }}$ and $\mathrm{I}_{\mathrm{css}}$ are very representative of the mean chip temperature with errors respectively lower than $1^{\circ} \mathrm{C}$ and $0.5^{\circ} \mathrm{C}$.

TABLE II. TEMPERAture MEASUREMENTS With $\mathrm{T}_{1}$

\begin{tabular}{|c|c|c|c|c|}
\hline TSEP & $\begin{array}{c}\mathbf{P} \\
(\mathbf{W})\end{array}$ & $\begin{array}{c}\mathbf{T}_{\text {TSEP }} \\
\left({ }^{\circ} \mathbf{C}\right)\end{array}$ & $\begin{array}{c}\mathbf{T}_{\text {meanIR }} \\
\left({ }^{\circ} \mathbf{C}\right)\end{array}$ & $\begin{array}{c}\text { Error } \\
\text { IR/TSEP } \\
\left({ }^{\circ} \mathbf{C}\right)\end{array}$ \\
\hline $\mathrm{V}_{\text {ce,sat }}$ & 45.8 & 71.0 & 69.8 & 1.2 \\
$\mathrm{~V}_{\text {ge, } \mathrm{I}}$ & 46.3 & 71.5 & 71.0 & 0.5 \\
$\mathrm{I}_{\text {css }}$ & 46.3 & 74.2 & 71.1 & 3.1 \\
\hline $\mathrm{V}_{\text {ce,sat }}$ & 70.7 & 100.1 & 98.1 & 2.0 \\
$\mathrm{~V}_{\mathrm{ge}, \mathrm{I}}$ & 70.6 & 99.2 & 98.6 & 0.6 \\
$\mathrm{I}_{\mathrm{css}}$ & 70.7 & 98.8 & 98.5 & 0.3 \\
\hline $\mathrm{V}_{\text {ce,sat }}$ & 95.1 & 125.2 & 123.8 & 1.4 \\
$\mathrm{~V}_{\text {ge }, \mathrm{I}}$ & 95.0 & 124.8 & 123.9 & 0.9 \\
$\mathrm{I}_{\mathrm{css}}$ & 95.1 & 124.1 & 123.8 & 0.3 \\
\hline
\end{tabular}

\section{Temperature measurements using IGBT $T_{2}$}

Table III shows the results using $T_{2}$ instead of $T_{1}$. The results are very close to these presented with $T_{1}$. In fact, $V_{\text {ge, } I}$ and $I_{\text {css }}$ give results very close to the mean IR temperature. The use of $V_{\text {ce,sat }}$ seems to be better than for $T_{1}$ but we can see that the measurement error can reach values higher than $1^{\circ} \mathrm{C}$. 
TABLE III. TEMPERATURE MEASUREMENTS WITH $\mathrm{T}_{2}$

\begin{tabular}{|c|c|c|c|c|}
\hline TSEP & $\begin{array}{c}\mathbf{P} \\
(\mathbf{W})\end{array}$ & $\begin{array}{c}\mathbf{T}_{\text {TSEP }} \\
\left({ }^{\circ} \mathbf{C}\right)\end{array}$ & $\begin{array}{c}\mathbf{T}_{\text {meanIR }} \\
\left({ }^{\circ} \mathbf{C}\right)\end{array}$ & $\begin{array}{c}\text { Error } \\
\text { IR/TSEP } \\
\left({ }^{\circ} \mathbf{C}\right)\end{array}$ \\
\hline $\mathrm{V}_{\text {ce,sat }}$ & 45.3 & 74.4 & 73.9 & 0.5 \\
$\mathrm{~V}_{\text {ge, } \mathrm{I}}$ & 44.9 & 74.7 & 74.1 & 0.6 \\
$\mathrm{I}_{\mathrm{css}}$ & 45.1 & 77.0 & 74.1 & 2.8 \\
\hline $\mathrm{V}_{\text {ce,sat }}$ & 69.4 & 101.9 & 100.5 & 1.4 \\
$\mathrm{~V}_{\text {ge,I }}$ & 69.0 & 101.2 & 100.7 & 0.4 \\
$\mathrm{I}_{\mathrm{css}}$ & 69.7 & 101.1 & 100.8 & 0.3 \\
\hline $\mathrm{V}_{\text {ce,sat }}$ & 94.0 & 127.6 & 127.0 & 0.6 \\
$\mathrm{~V}_{\text {ge,I }}$ & 94.2 & 128.0 & 127.3 & 0.7 \\
$\mathrm{I}_{\mathrm{css}}$ & 93.7 & 127.5 & 127.3 & 0.1 \\
\hline
\end{tabular}

\section{Temperature measurements using IGBT $T_{1} / / T_{2}$}

As shown in Fig. 1, there are four holes in the corners of the power module. With these holes, it is possible to fix this module with screws on the base plate (Fig. 2). A torque adjustment of the power module mounting conditions permits to modify the thermal resistance between each IGBT chip and the cooling system. So, each IGBT chip temperature can be adjusted in order to perform a TSEP evaluation in different thermal conditions. For example, if this torque is lower in the left hand side of the module, the temperature of IGBT $T_{1}$ is higher than this of IGBT $\mathrm{T}_{2}$.

Table IV proposes a comparison between results obtained with infrared temperature measurements and with TSEPs in the case of two paralleled IGBT chips. Three cases are studied. In the first one, the mean temperatures of both IGBT are about the same. In the second, IGBT $\mathrm{T}_{1}$ is hotter than IGBT $T_{2}$. In the last case, IGBT $T_{2}$ is hotter than IGBT $T_{1}$. For each case, the total power level is relatively low $(\approx 40 \mathrm{~W})$ and the variation of the junction temperature is obtained modifying the temperature of the coolant liquid. The power dissipation is low in order to have a very low temperature variation on each IGBT chip surface (about $5^{\circ} \mathrm{C}$ ). The last column represents the difference between $\mathrm{T}_{\mathrm{TSEP}}$ and $\mathrm{T}_{\text {meanIR }}$ (which is the mean value of the mean temperature of $\mathrm{T}_{1} \mathrm{~T}_{\text {meanIR }} \mathrm{T} 1$ and the mean temperature of $T_{2} T_{\text {meanIR T2}}$ ). Next to this column is given the difference between $T_{\text {meanIR T1 }}$ and $T_{\text {meanIR T2 }}$. The results given by $I_{\text {css }}$ at lower temperatures has not to be taken into account because this TSEP was not calibrated for this temperature level (Fig. 18).

If both IGBTs have approximately the same temperature, the three indirect temperature measurements with TSEP conduct to a good correlation with the mean IR temperature measurement $\left(\mathrm{T}_{\text {meanIR }}\right)$. Especially the results given by $\mathrm{I}_{\mathrm{css}}$ are very good, the temperature difference between $T_{\text {meanIR }}$ and $\mathrm{T}_{\mathrm{TSEP}}$ being lower than $0.1^{\circ} \mathrm{C} . \mathrm{V}_{\text {ce,sat }}$ also gives very good results, the temperature difference being lower than $1^{\circ} \mathrm{C}$. The worst results are given by $\mathrm{V}_{\mathrm{ge}, \mathrm{I}}$. The measurement error in this last case could be due to the extrapolation method because the threshold voltage of each IGBT being different, the current repartition is totally different in each IGBT and the selfheating (during calibration) or the cooling (during temperature measurements) of each semiconductor device are completely different. In the case of $\mathrm{I}_{\mathrm{css}}$ the same problem exists but this TSEP is the sum of the saturation currents of $T_{1}$ and $T_{2}$. The cooling and self-heating of the device being linear phenomena, the results seem to be not affected by this problem.

If IGBTs temperatures are not equal, the chip temperature evaluation by TSEP may conduct to significant errors over $3{ }^{\circ} \mathrm{C}$ in comparison with the mean IR temperatures. If $T_{1}$ is hotter than $\mathrm{T}_{2}, \mathrm{I}_{\mathrm{css}}$ is still the best TSEP but the temperature difference between all TSEP and IR measurements is largely higher than in the previous case. On the contrary, $\mathrm{V}_{\mathrm{ge,I}}$ seems to be the best TSEP if IGBT $T_{2}$ is hotter than IGBT $T_{1}$. Results given by $\mathrm{V}_{\text {ce,sat }}$ do not depend on the temperature repartition between both IGBT.

TABLE IV. TEMPERATURE MEASUREMENTS With $\mathrm{T}_{1} / / \mathrm{T}_{2}$

\begin{tabular}{|c|c|c|c|c|c|c|c|}
\hline $\begin{array}{c}\text { Test } \\
\text { conditions }\end{array}$ & TSEP & $\begin{array}{l}\mathbf{T}_{\text {TSEP }} \\
\left({ }^{\circ} \mathrm{C}\right)\end{array}$ & \begin{tabular}{|c|}
$\mathbf{T}_{\text {mean IR }}$ \\
$\mathbf{T}_{1}$ \\
$\left({ }^{\circ} \mathrm{C}\right)$ \\
\end{tabular} & $\begin{array}{l}\mathbf{T}_{\text {mean IR }} \\
\mathrm{T}_{2}\left({ }^{\circ} \mathrm{C}\right)\end{array}$ & $\begin{array}{c}T_{\text {meanIR }} \\
\left({ }^{\circ} \mathrm{C}\right)\end{array}$ & \begin{tabular}{|c|}
$\mathbf{T}_{\text {meaniR T1 }}$ \\
- \\
$\mathbf{T}_{\text {meanIR T2 }}$ \\
\end{tabular} & \begin{tabular}{|c|} 
Error \\
IR/TSEP \\
$\left({ }^{\circ} \mathrm{C}\right)$ \\
\end{tabular} \\
\hline \multirow{9}{*}{$\begin{array}{c}\mathrm{T}_{1} \text { and } \mathrm{T}_{2} \text { with } \\
\text { the same } \\
\text { temperature }\end{array}$} & $\mathrm{V}_{\mathrm{ce}, \mathrm{sat}}$ & 76.5 & 75.8 & 75.6 & 75.7 & 0.2 & 0.8 \\
\hline & $\mathrm{V}_{\mathrm{ge}, \mathrm{I}}$ & 78.3 & 77.0 & 76.9 & 76.9 & 0.1 & 1.4 \\
\hline & $\mathrm{I}_{\mathrm{css}}$ & 78.6 & 76.4 & 76.4 & 76.4 & 0.0 & 2.2 \\
\hline & $\mathrm{V}_{\text {ce,sat }}$ & 108.5 & 108.3 & 107.3 & 107.8 & 1.0 & 0.7 \\
\hline & $\mathrm{V}_{\mathrm{ge}, \mathrm{I}}$ & 108.9 & 108.3 & 107.2 & 107.7 & 1.1 & 1.2 \\
\hline & $\mathrm{I}_{\mathrm{css}}$ & 107.8 & 108.3 & 107.3 & 107.8 & 1.0 & -0.1 \\
\hline & $\mathrm{V}_{\mathrm{ce}, \mathrm{sat}}$ & 129.6 & 129.9 & 128.2 & 129.1 & 1.7 & 0.5 \\
\hline & $\mathrm{V}_{\mathrm{ge}, \mathrm{I}}$ & 129.9 & 129.9 & 128.2 & 129.0 & 1.7 & 0.8 \\
\hline & $\mathrm{I}_{\mathrm{css}}$ & 128.9 & 129.9 & 128.2 & 129.0 & 1.7 & -0.1 \\
\hline \multirow{9}{*}{$\begin{array}{c}\mathrm{T}_{1} \text { hotter than } \\
\mathrm{T}_{2}\end{array}$} & $\mathrm{~V}_{\text {ce,sat }}$ & 93.6 & 98.7 & 84.4 & 91.6 & 14.3 & 2.1 \\
\hline & $\mathrm{V}_{\mathrm{ge}, \mathrm{I}}$ & 95.0 & 98.9 & 84.7 & 91.8 & 14.2 & 3.2 \\
\hline & $\mathrm{I}_{\mathrm{css}}$ & 94.4 & 99.2 & 85.1 & 92.1 & 14.1 & 2.3 \\
\hline & $\mathrm{V}_{\text {ce,sat }}$ & 113.0 & 117.9 & 104.9 & 111.4 & 13.0 & 1.6 \\
\hline & $\mathrm{V}_{\mathrm{ge}, \mathrm{I}}$ & 113.8 & 117.6 & 104.7 & 111.1 & 12.9 & 2.7 \\
\hline & $\mathrm{I}_{\mathrm{css}}$ & 112.6 & 117.6 & 104.6 & 111.1 & 13.0 & 1.5 \\
\hline & $\mathrm{V}_{\text {ce,sat }}$ & 132.4 & 136.9 & 125.4 & 131.2 & 11.5 & 1.2 \\
\hline & $\mathrm{V}_{\mathrm{ge}, \mathrm{I}}$ & 133.0 & 136.7 & 125.2 & 130.9 & 11.5 & 2.0 \\
\hline & $\mathrm{I}_{\mathrm{css}}$ & 132.0 & 136.8 & 125.3 & 131.0 & 11.5 & 0.9 \\
\hline \multirow{9}{*}{$\begin{array}{c}\mathrm{T}_{2} \text { hotter than } \\
\mathrm{T}_{1}\end{array}$} & $\mathrm{~V}_{\mathrm{ce}, \mathrm{sat}}$ & 90.9 & 81.6 & 96.2 & 88.9 & -14.6 & 2.0 \\
\hline & $\mathrm{V}_{\mathrm{ge}, \mathrm{I}}$ & 88.7 & 80.7 & 95.3 & 88.0 & -14.6 & 0.8 \\
\hline & $\mathrm{I}_{\mathrm{css}}$ & 87.8 & 80.7 & 95.4 & 88.0 & -14.7 & -0.3 \\
\hline & $\mathrm{V}_{\text {ce,sat }}$ & 108.4 & 101.3 & 112.7 & 107.0 & -11.4 & 1.4 \\
\hline & $\mathrm{V}_{\mathrm{ge}, \mathrm{I}}$ & 107.6 & 101.3 & 112.7 & 107.0 & -11.4 & 0.6 \\
\hline & $\mathrm{I}_{\mathrm{css}}$ & 106.2 & 101.4 & 112.8 & 107.1 & -11.4 & -0.9 \\
\hline & $\mathrm{V}_{\text {ce,sat }}$ & 132.9 & 124.8 & 138.4 & 131.6 & -13.6 & 1.3 \\
\hline & $\mathrm{V}_{\mathrm{ge}, \mathrm{I}}$ & 131.9 & 124.9 & 138.7 & 131.8 & -13.8 & 0.1 \\
\hline & $\mathrm{I}_{\mathrm{css}}$ & 131.3 & 125.2 & 139.2 & 132.2 & -14.0 & -0.9 \\
\hline
\end{tabular}

\section{E. Discussion}

$\mathrm{V}_{\text {ce,sat }}$ is the most used TSEP in the case of thermal characterizations of power packages. All experimental results presented in this paper and in [6] show that the temperature obtained with this TSEP is always higher than the mean chip surface temperature. The temperature difference between $\mathrm{T}_{\mathrm{TSEP}}$ and $\mathrm{T}_{\text {meanIR }}$ is low is the case of an homogeneous temperature distribution (Table IV $-\mathrm{T}_{1}$ and $\mathrm{T}_{2}$ with the same temperature) and higher if the temperature difference is larger (Table II, Table III and Table IV in other cases).

Table IV also shows that the temperature difference values (last column) given if $T_{1}$ is hotter than $T_{2}$ or if $T_{2}$ is hotter than $\mathrm{T}_{1}$ are approximately the same. For example, if $\mathrm{T}_{\text {meanIR }} \approx 90^{\circ} \mathrm{C}$, the temperature difference equals $2.1^{\circ} \mathrm{C}$ when $\mathrm{T}_{\text {meaniR }}$ ${ }_{\mathrm{T} 1}>\mathrm{T}_{\text {meanIR }} \mathrm{T}_{2}$ and $2.0^{\circ} \mathrm{C}$ when $\mathrm{T}_{\text {meanIR }} \mathrm{T}_{2}>\mathrm{T}_{\text {meanIR }} \mathrm{T}_{1}$. If $\mathrm{T}_{\text {mean } \mathrm{R}} \approx 110^{\circ} \mathrm{C}$, the temperature difference is respectively $1.6^{\circ} \mathrm{C}$ and $1.4^{\circ} \mathrm{C}$. If $\mathrm{T}_{\text {meanIR }} \approx 130^{\circ} \mathrm{C}$, it is respectively $1.2^{\circ} \mathrm{C}$ and 
$1.3^{\circ} \mathrm{C}$. Therefore the measurement with $\mathrm{V}_{\text {ce,sat }}$ as TSEP depends on the temperature distribution but is not influenced by the temperature repartition between several IGBT chips. It is mainly due to the fact that this TSEP has a low variation from one chip to another with the same reference (Fig. 13). Because most power modules are made with several paralleled IGBT chips, this TSEP is very well adapted for their thermal characterization thanks to his robustness.

The other TSEPs $\left(\mathrm{V}_{\mathrm{ge}, \mathrm{I}}\right.$ and $\left.\mathrm{I}_{\mathrm{css}}\right)$ are useful for the measurement of an IGBT chip temperature (Table II and Table III). But, as shown by Table IV, the thermal disequilibrium conditions $\left(T_{1}\right.$ hotter than $T_{2}$ or $T_{2}$ hotter than $\mathrm{T}_{1}$ ) conduct to a more or less good correlation between these TSEP and IR temperature measurements. In the case of a temperature disequilibrium between several chips, the temperature measurements give also good results but the reproducibility is not satisfactory. For example, using $\mathrm{I}_{\mathrm{css}}$ as TSEP and $\mathrm{T}_{\text {meanIR }} \approx 110^{\circ} \mathrm{C}$, the difference between $\mathrm{T}_{\text {TSEP }}$ and $\mathrm{T}_{\text {mean,IR }}$ is $1.5^{\circ} \mathrm{C}$ if $\mathrm{T}_{\text {meanIR } \mathrm{T} 1}>\mathrm{T}_{\text {meanIR } \mathrm{T} 2}$ and $-0.9^{\circ} \mathrm{C}$ if $\mathrm{T}_{\text {meanIR }}$ ${ }_{\mathrm{T} 2}>\mathrm{T}_{\text {meanIR }} \mathrm{T} 1$. These results are the consequences of two combined factors which are effective chips temperatures and TSEP characteristics differences of each IGBT (Fig. 16 and 18). In conclusion $\mathrm{V}_{\mathrm{ge}, \mathrm{I}}$ and $\mathrm{I}_{\mathrm{css}}$ can be used for the thermal characterization of power modules using only one chip per switch. In the case of paralleled power devices, their use induces large temperature measurement errors due to the lack of reproducibility.

\section{CONCLUSION}

In this paper an experimental setup was first proposed in order to compare IGBT chip temperature measurements using three TSEPs and an IR camera. These measurements were carried out using only one IGBT or two paralleled IGBTs. The power dissipation was made in the saturation region of the semi-conductor devices (full conduction - $\mathrm{V}_{\mathrm{ge}}=15 \mathrm{~V}$ ). The IR measurement procedure was made with caution in order to obtain the more accurate chip temperature measurements: the emissivity of the black paint was estimated and a numerical procedure was developed in order to extract the real temperature of the active part of the device excluding the electrical connections, the inactive areas, and also the artifacts due to radiative reflections.

With these experimental and numerical tools, a calibration campaign was first carried out. Results were obtained for easch TSEP. Large differences were obtained between both IGBT in the case of $\mathrm{V}_{\mathrm{ge}, \mathrm{I}}$ and $\mathrm{I}_{\mathrm{css}}$ due to the variation of the threshold voltage from one chip to another with the same reference. Finally a comparison between temperature measurements given by the TSEPs and IR measurements was presented, the IGBTs being in dissipation conditions. All TSEPs in all conditions give temperature results close to these provided by IR measurements. However $\mathrm{I}_{\mathrm{css}}$ seems to give the best accordance in case of using only one IGBT. If both IGBT are paralleled, this TSEP and $\mathrm{V}_{\mathrm{ge}, \mathrm{I}}$ give results depending on the temperature repartition between both chips because of the variation of these TSEPs from one chip to another. That is not the case for $\mathrm{V}_{\text {ce,sat }}$ which is a more robust TSEP. Therefore this parameter seems to be the best for the thermal characterization of power modules with paralleled power devices.

\section{ACKNOWLEDGMENT}

We would like to gratefully thank Valeo company for its help especially for the realization of the power modules, and the CNRS for the funding (GdR SEEDS).

\section{REFERENCES}

[1] M.P. Rodriguez, N.Y.A. Shammas, A.T. Plumpton, D. Newcombe ,D.E. Crees, "Static and dynamic finite element modelling of thermal fatigue effects in insulated gate bipolar transistor modules", Microelectronics Reliability, vol. 40, pp. 455-463, 2000.

[2] D-L. Blackburn, "Temperature Measurements of Semiconductor Devices - A Review", 20th Annual Semiconductor Thermal Measurement and Management Symposium, pp. 70-80, 2004.

[3] U. Scheuermann, S. Schuler, "Power cycling results for different control strategies", Microelectronics Reliability, 2010.

[4] S. Carubelli, Z. Khatir, "Experimental validation of a thermal modelling method dedicated to multichip power modules in operating conditions", Microelectronics Journal, vol. 34, pp. 1143-1151, 2003.

[5] L-M. Hillkirk, B. Breitholtz, M. Domeij, "Space and time resolved surface temperature distributions in Si power diodes operating under self-heating conditions", Solid-State Electronics, Vol. 45, pp. 20572067, 2001.

[6] R. Schmidt, U. Scheuermann, "Using the chip as a temperature sensorThe influence of steep lateral temperature gradients on the Vce(T)measurement", 13th European Conference on Power Electronics and Applications, 2009.

[7] W. Brekel, T. Duetemeyer, G. Puk, O. Schilling, "Time Resolved In Situ Tvj Measurements of $6.5 \mathrm{kV}$ IGBTs during Inverter Operation", Proceedings PCIM Europe, pp.808-813, 2009.

[8] Z. JakopoviC, Z. Bencic, F. Kolonic, "Important Properties of Transient Thermal Impedance for MOS-gated Power Semiconductors", IEEE International Symposium on Industrial Electronics, pp. 574-578, 1999.

[9] D. Berning, J. Reichl, A. Hefner, M. Hernandez, C. Ellenwood, J-S. Lai, "High speed IGBT module transient thermal response measurements for model validation", 38th IAS Annual Meeting Industry Applications Conference, pp. 1826-1832, 2003.

[10] A. Ammous, B. Allard, H. Morel, "Transient temperature measurements and modeling of IGBT's under short circuit", IEEE Transactions on Power Electronics, vol. 13, no 1, pp. 12-25, 1998.

[11] D. L. Blackburn, "Temperature measurements of semiconductor devices - a review," Twentieth Annual IEEE Semiconductor Thermal Measurement and Management Symposium (IEEE Cat. No.04CH37545), pp. 70-80, 2004.

[12] X. Cao, T. Wang, G-Q. Lu, K.D.T. Ngo, "Characterization of lead-free solder and sintered nano-silver die-attach layers using thermal impedance", International Power Electronics Conference, pp. 546-552, 2010. 